\title{
A very unusual case of interstitial lung disease
}

\begin{abstract}
Cotton dust exposure has been implicated in causing diseases like byssinosis and obstructive airway diseases like COPD and asthma. Long-term exposure to cotton dust causing interstitial lung disease and pulmonary fibrosis has been sparsely reported in the literature. Here, we report a case of an individual with long-term cotton dust exposure who presented with typical symptoms of interstitial lung disease and was managed conservatively.
\end{abstract}

Key words: cotton dust, byssinosis, interstitial lung disease, pulmonary fibrosis

Adv Respir Med. 2021; 89: 524-527

\section{Introduction}

Long-term exposure to cotton fibres has been classically associated mostly with byssinosis and airway diseases like chronic obstructive pulmonary disease and asthma [1,2]. The exposure constitutes of broken cotton fibres, bracts and pericarps, as well as to bacteria and fungi on the surface of these cotton products. Cotton-induced pulmonary fibrosis and pneumoconiosis has been rarely reported in the literature [3, 4]. Here, we report a case of a cotton mill worker who presented with an insidious onset of breathlessness and cough who was diagnosed with cotton-induced interstitial lung disease and was managed conservatively.

\section{Material and methods}

A 65-year-old male who was a non-smoker and had a history of working in a cotton mill for 30 years presented with a history of sudden onset, progressive breathlessness and dry cough that had been present for six months. His work history included working in a cotton mill for 8 hours per day, 5 days a week, for 30 years. He was initially evaluated at another hospital, was managed conservatively, and was even started on oral steroids. He had symptomatic improvement at first but later reported to our hospital with fever, increased cough, and breathlessness that had been present for a two-week duration. He stated that he used to feel better on holidays and weekends but that his symptoms had worsened as of late. There was no history of joint pains or any other connective tissue disease. Interestingly, he stated that he had noticed similar complaints in some of his co-workers. On examination, he was tachycardic (pulse - 110/min), tachypnoeic (respiratory rate $-30 / \mathrm{min}$ ), and hypoxic $\left(\mathrm{SpO}_{2}-80 \%\right.$ at room air). He had grade II clubbing in both hands. On auscultation, he had bilateral, symmetrical fine inspiratory crackles in the infrascapular and infra-axillary areas. There were no signs of any connective tissue disorders. On evaluation, his complete blood count, liver function tests, and renal function tests were within normal limits. His chest x-ray showed bilateral reticular opacities in both lower zones (Figure 1A). He underwent high-resolution computed tomography of the chest which showed multifocal areas of honeycombing with bi-basal predominance, extensive areas of interlobular septal thickening, a few areas of ground-glass attenuation in bilateral lung fields (Figure 1B, 1C), and discretely enlarged mediastinal lymph 

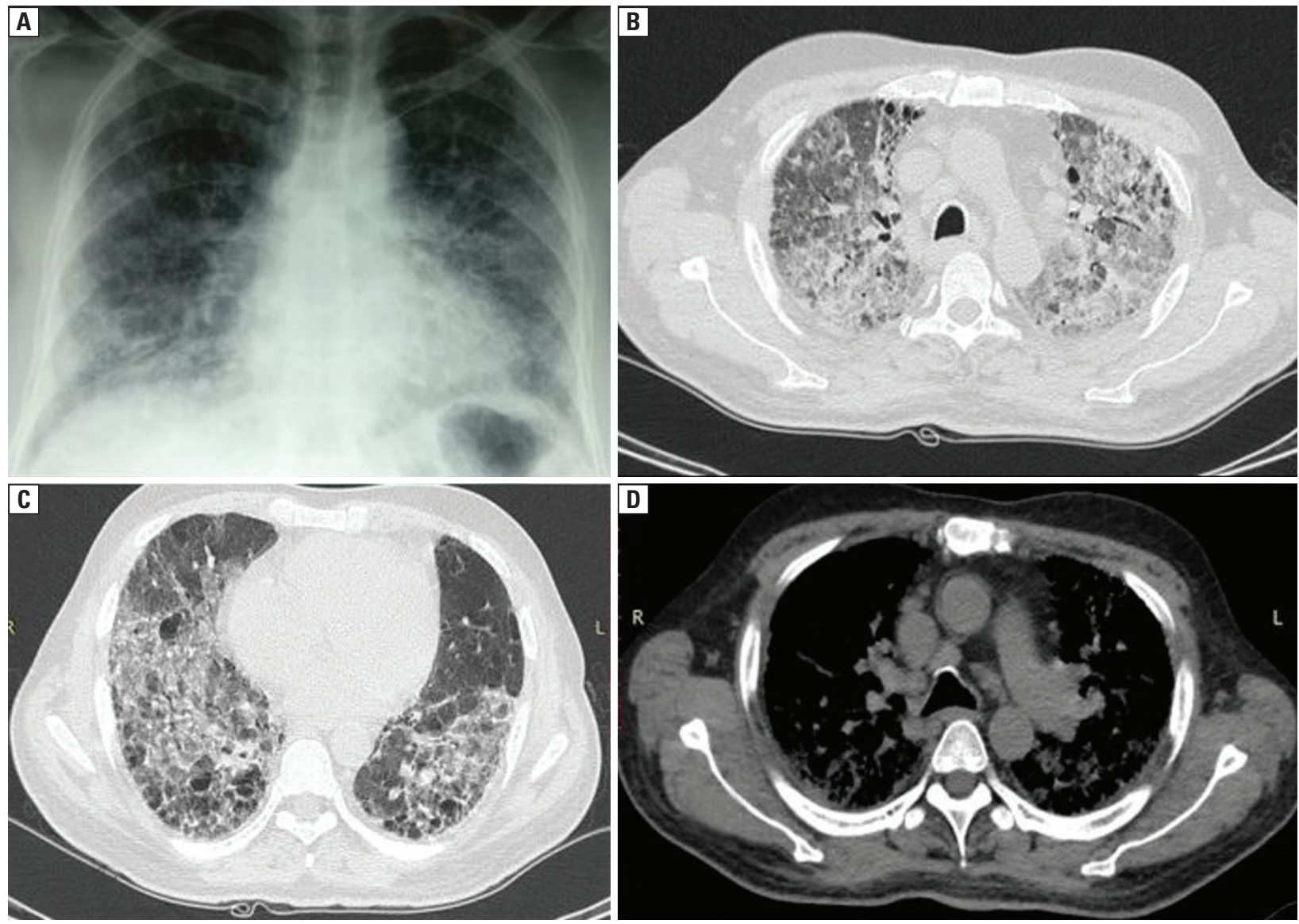

Figure 1. A. Chest x-ray of the patient showing bilateral reticular opacities; B. C. Extensive interlobular and intralobular septal thickening, traction bronchiectasis, microcystic and macrocystic honeycombing in bilateral lung fields. Extensive ground-glass opacities along with areas of air trapping also seen scattered in the lungs bilaterally giving mosaic attenuation throughout the lung fields; D. High-resolution computed tomography of the chest showing bilateral pleural involvement with a shaggy pleural outline. Multiple discrete enlarged mediastinal lymph nodes seen

nodes (Figure 1D). His spirometry results were as follows: forced expiratory volume in 1 second $\left(\mathrm{FEV}_{1}\right)-1.55$ litres (68\% of the predicted), forced vital capacity (FVC) - 1.65 litres ( $54 \%$ of the predicted), and a normal ratio of $\mathrm{FEV}_{1} / \mathrm{FVC}$ - 93.94\%. There was no post-bronchodilator reversibility and there was evidence of small airway obstruction. His diffusion capacity of the lungs for carbon monoxide $\left(\mathrm{D}_{\mathrm{LCO}}\right)$ showed a moderate diffusion defect (50\%). The results of the 6 minute walk test showed that he had a decreased walk distance of 120 metres with significant desaturation $\left(10 \%\right.$ fall of $\mathrm{SpO}_{2}$ from baseline) (Table 1). His arterial blood gas at room air showed hypoxemia $\left(\mathrm{pH}-7.40, \mathrm{pO}_{2}-50 \mathrm{~mm}\right.$ $\mathrm{Hg}$, and $\mathrm{pCO}_{2}-41 \mathrm{~mm} \mathrm{Hg}$ ). His connective tissue disorder profile (rheumatoid factor, anti-cyclic citrullinated peptide, anti-nuclear antibody, C-reactive protein, and extractable nuclear antigen antibody levels) was within normal limits. $\mathrm{He}$ was diagnosed with cotton dust-induced interstitial lung disease based on clinical, radiologi- cal, and spirometric criteria, and was managed with long acting bronchodilators and inhaled steroid inhalers with oxygen supplementation, while at the same time tapering the dose of oral steroids. He was advised and counselled about complete cessation of cotton dust exposure and even regarding potentially changing his profession. He is presently symptomatically better with improved exercise tolerance.

\section{Discussion}

Cotton dust exposure constitutes a major occupational health hazard in our country. The effect of cotton exposure can be varied and depends on the duration of exposure, site of exposure, effect of the specific component of cotton dust, presence of fungi, and presence of other factors such as smoking. The most common respiratory diseases associated with cotton dust exposure are byssinosis and airway diseases such as COPD and asthma $[2,4]$. 
Table 1. The details of pulmonary function testing

\begin{tabular}{|c|c|c|}
\hline Spirometry & Pre & Post \\
\hline $\mathrm{FEV}_{1}$ & $1.55 \mathrm{~L}(68 \%)$ & $1.58 \mathrm{~L}(69 \%)$ \\
\hline FVC & $1.65 \mathrm{~L}(54 \%)$ & $1.78 \mathrm{~L}(56 \%)$ \\
\hline $\mathrm{FEV}_{1} / \mathrm{FVC}$ & $93.94 \%$ & $88 \%$ \\
\hline DLCO & $50 \%$ & $9.4 \mathrm{~mL} / \mathrm{min} / \mathrm{mm} \mathrm{Hg}$ \\
\hline 6MWT & $120 \mathrm{~m}$ & $\begin{array}{l}\text { With significant desaturation } \\
\text { (> }>10 \% \text { from baseline) }\end{array}$ \\
\hline
\end{tabular}

Byssinosis can be acute or chronic. It generally presents with a history of cough, chest tightness, and breathlessness after long-term exposure to cotton dust. It classically has a history of increasing severity of symptoms after returning to work after holidays/breaks (Monday asthma) and typically worsens as the day progresses. Acute byssinosis has been characterized by symptoms occurring after a short duration of exposure and by a fall in FEV1 of more than 30\% [2, 7].

The other most common diseases associated with cotton dust exposure are airway diseases like asthma and COPD. Early stages of byssinosis can have features of asthma like reversible airflow limitation and airway hyperresponsiveness. There can be large changes in pre- and postwork FEV1, which is also termed 'cross-shift drop' in $\mathrm{FEV}_{1}$ [2]. These symptoms can become more severe and frequent with long-term exposure and patients can develop progressive breathlessness and cough with expectoration resembling COPD. These patients can have a post bronchodilator $\mathrm{FEV}_{1} / \mathrm{FVC}$ (forced expiratory volume in 1 second to forced vital capacity) ratio $<0.7[2,4,5]$.

Cotton dust exposure has rarely been reported to cause pneumoconiosis/interstitial lung disease and pulmonary fibrosis except for some case reports and post-mortem reports [1, 3, 4, 6]. Pneumoconiosis due to cotton dust is different than pneumoconiosis due to inorganic dust as it is likely due to hypersensitivity pneumonitis secondary to organic dust inhalation produced during processing of cotton in cotton industries. The pathogenesis may also involve production of nitric oxide from alveolar macrophages and type-2 epithelial cells from lipopolysaccharides (LPS) present in cotton dust (component of outer membrane of various Gram-negative bacteria) [3]. This nitric oxide reacts with superoxide to initiate the cascade of inflammatory cytokine production which may cause structural damage and fibrosis. The endotoxin has been implicated in causing airway inflammation, hyperreactivity, and airflow obstruction causing byssinosis [4]. Patients with cotton dust-induced pneumoconiosis generally present with insidious onset breathlessness with dry cough and a retrospective history of prolonged exposure to cotton dust. On examination, they are hypoxic at room air. On auscultation, they have bilateral inspiratory crackles, as was the case in our patient [3]. The diagnosis can be confirmed radiologically and chest radiographs of these patients typically show bilateral basal interstitial infiltrates with reduced lung volumes. In these patients, computed tomography of the chest can show fibrosis with peribronchiolar distribution, centrilobular nodules with a 'tree in bud' appearance, and areas of ground-glass opacities [1, 3, 7]. Our patient also had features of diffuse fibrosis with ground-glass opacities in bilateral lung fields.

Byssinosis generally causes a reversible decrease in $\mathrm{FEV}_{1}$ but as the disease progresses, the changes can become irreversible. Patients with pneumoconiosis generally show a mixed defect. Our case also had a mixed defect on spirometry and had a diffusion defect which indicated the severity of the disease. These patients generally have exercise-induced hypoxemia. On the other hand, resting hypoxia indicates severe disease and fibrosis [2, 7].

Bronchoalveolar lavage (BAL) and lung biopsy have major roles in this disease as they can confirm the diagnosis. BAL differential cytology can help differentiate byssinosis from other differential diagnoses such as hypersensitivity pneumonitis (lymphocyte predominant). The cotton fibres deposited in the lungs can form byssinosis bodies which causes a foreign body reaction of the lung tissue [3, 4, 6, 7]. In our case, the diagnosis of cotton dust-induced interstitial lung disease was made on the basis of clinical, radiological, and pulmonary function tests. We did not perform a bronchoscopic procedure as the patient was hypoxemic at room air and had a significant history of exposure to cotton dust. Clinical findings and computed tomography of the chest confirmed interstitial lung disease. All secondary causes were excluded.

The treatment of pneumoconiosis consists mainly of cessation of exposure [3, 8]. According to a prospective cohort study consisting of 447 cotton textile workers and 472 unexposed silk textile workers with 25 years of follow-up and based on spirometry and respiratory questionnaire data, the authors confirmed that ces- 
sation of cotton dust exposure is associated with improvement in lung function and respiratory symptoms [8]. Patients should also be counselled about changing their profession. Corticosteroids also have a role in reducing inflammation. Supportive treatment includes supplementary oxygen, bronchodilators, and prompt treatment of secondary bacterial infections $[3,7,8]$.

\section{Conclusion}

Cotton dust exposure-related diseases are a major cause of increased morbidity in developing countries. The manifestation of disease also depends on duration of exposure, site of exposure, effect of the specific component of the cotton dust, presence of fungi, and presence of other factors like smoking. The most common respiratory diseases associated with cotton dust exposure are byssinosis and airway diseases like COPD and asthma. Cotton dust-related interstitial lung disease has rarely been reported on in the literature and should be kept in mind by treating pulmonologists while managing patients with similar clinical presentations.

\section{Conflict of interest}

None declared.

\section{References:}

1. Mittal R, Gupta P, Chhabra SK. Occupational bronchiolitis induced by cotton dust exposure in a nonsmoker. Indian J Occup Environ Med. 2016; 20(2): 118-120, doi: 10.4103/00195278.197550, indexed in Pubmed: 28194087.

2. Lai PS, Christiani DC. Long-term respiratory health effects in textile workers. Curr Opin Pulm Med. 2013; 19(2): 152-157, doi: 10.1097/MCP.0b013e32835cee9a, indexed in Pubmed: 23361196.

3. Gothi D, Joshi JM. An unusual interstitial lung disease. Ann Thorac Med. 2012; 7(3): 162-164, doi: 10.4103/18171737.98851, indexed in Pubmed: 22924076.

4. Khan AJ, Nanchal R. Cotton dust lung diseases. Curr Opin Pulm Med. 2007; 13(2): 137-141, doi: 10.1097/MCP.0b013e32802C7ceb, indexed in Pubmed: 17255805 .

5. Beckett WS. Occupational respiratory diseases. N Engl J Med. 2000; 342(6): 406-413, doi: 10.1056/NEJM200002103420607. indexed in Pubmed: 10666432.

6. Rüttner JR, Spycher MA, Engeler ML. Pulmonary fibrosis induced by cotton fibre inhalation. Pathol Microbiol (Basel). 1968; 32(1): 1-14, doi: 10.1159/000162041, indexed in Pubmed: 5711260.

7. Jindal SK, Aggarwal AN, Gupta D. Dust-induced interstitial lung disease in the tropics. Curr Opin Pulm Med. 2001; 7(5): 272-277, doi: 10.1097/00063198-200109000-00004, indexed in Pubmed: 11584175.

8. Shi J, Hang JQ, Mehta AJ, et al. Long-term effects of work cessation on respiratory health of textile workers: a 25-year follow-up study. Am J Respir Crit Care Med. 2010; 182(2): 200-206, doi: 10.1164/rccm.200903-0329OC, indexed in Pubmed: 20339150. 